DOI: 10.36695/2219-5521.3.2019.47

УДК 343.01

\title{
Ш.Т. САМЕДОВА
}

Шахла Тофик кызы Самедова, доктор юридических наук, профессор Бакинского государственного университета*

ORCID: 0000-0001-6995-7140

\section{О ПОСТРОЕНИИ САНКЦИЙ И ФОРМАЛИЗАЦИИ НАЗНАЧЕНИЯ НАКАЗАНИЯ В УГОЛОВНОМ ПРАВЕ В АЗЕРБАЙДЖАНСКОЙ РЕСПУБЛИКЕ}

Анализ Особенной части УК Азербайджанской Республики 1999 г. показывает, что построение санкций, чисто в юридико-техническом отношении имея положительную тенденцию по сравнению с предыдущими УК, все же далеко несовершенно. В УК 1999 г. по конструкции все санкции являются относительно определенными и делятся всего на два вида: единичные и альтернативные. Сохранилась тенденция конструирования и альтернативных санкций за наиболее и за наименее общественно опасные деяния. Принципиально новым в УК 1999 г. при конструировании санкций Особенной части является то, что вид и мера наказания в конкретной санкции предопределяет отношение того или иного деяния к определенной категории преступления. А от категории совершенного преступления зависят правила назначения и освобождения от наказания, наступление и порядок применения правовых последствий, определяемых в нормах и институтах Общей части УК. Изменилась и юридическая техника при перечислении видов наказания в альтернативных санкциях: от менее строгого к более строгому.

Учитывая, что институт классификации преступлений в зависимости от тяжести характера и степени общественной опасности на четыре категории является новеллой УК 1999 г., естественно, конструирование системы санкций Особенной части должно было базироваться на совершенно новых принципах и правилах. Однако, к сожалению, законодателю это не удалось, т.к. построение санкций Особенной части изначально базируется на несовершенном институте классификации преступлений, в котором границы категорий четко не определены. Поэтому система санкций Особенной части УК 1999 г. в целом дисбалансирована, а также страдает другими серьезными недостатками. При этом изменения, внесенные в ст. 15 УК Азербайджанской Республики с целью совершенствования института классификации преступлений в 2001 г., а также последующие изменения и дополнения Особенной части УК только усугубили этот процесс.

При построении санкций Особенной части УК обязательно должны учитываться все основные юридические признаки соответствующих видов преступлений - характер и степень их общественной опасности, форма вины, обязательные элементы состава преступления. По справедливому мнению Н.И. Загородникова, санкция является результатом социальной оценки преступления и при ее построении должны учитываться объективные и субъективные признаки преступления, т.к. именно при построении санкции происходит реализация уголовно-правовой политики государства ${ }^{1}$.

Устанавливая уголовно-правовую санкцию основного состава преступления, законодатель должен ориентироваться на характер и степень общественной опасности деяния. При построении санкции основного состава, на наш взгляд, главное значение имеет социальная ценность объекта посягательства, что находит свое выражение в характере общественной опасности деяния. Кроме того, на вид и меры наказания в санкции основного состава оказывают влияние характер действий (бездействий), составляющих объективную сторону преступления, способ совершения преступления, характер и тяжесть наступивших последствий и др. Например, совершение преступлений насильственного характера свидетельствует об агрессивном поведении виновного, поэтому санкция должна обязательно содержать такое наказание, как лишение свободы. Или же за совершение преступлений корыстной направленности обязательно, на наш взгляд, следует в зависимости от категории совершенного преступления конструировать санкцию в альтернативном порядке с учетом видов наказаний имущественного характера (штраф или исправительные работы) или же конструиро-

() Ш.Т. Самедова, 2019

* Shahla Samadova, Dr. Hab. in Law, Professor of Baku State University 
вать единичную кумулятивную санкцию, а в качестве дополнительного вида наказания обязательно предусматривать штраф.

Санкции квалифицированных и привилегированных видов преступления конструируются больше с учетом остальных элементов состава преступления, в том числе и факультативных, которые сравнительно увеличивают (в квалифицированных составах) или уменьшают (в привилегированных составах) степень общественной опасности деяния. С учетом указанных обстоятельств законодатель должен конструировать вид и пределы уголовно-правовых санкций. При этом санкции квалифицированных составов должны быть строже основных, а санкции основных составов при законодательном выделении привилегированных составов этого же вида преступления должны быть строже санкций привилегированных составов.

Учет субъективных признаков преступления также оказывает большое влияние на построение уголовно-правовых санкций. Среди них можно назвать форму вины, законодательно определенные в качестве обязательных элементов вторичные признаки субъекта и субъективной стороны (специальные признаки субъекта преступления, мотивы и цели преступления, в том числе наличие состояния аффекта). Так, за неосторожные преступления ответственность наступает лишь в специально оговоренных в законе случаях (ст. 24.2 УК). Санкции неосторожных преступлений являются сравнительно менее строгими, чем санкции умышленных преступлений одного и того же вида. Законодатель ограничил максимум наказания за неосторожные преступления сроком лишения свободы в 12 лет, не включив неосторожные преступления в категорию особо тяжких преступлений.

При построении санкций большое значение имеет и практика назначения судами конкретных наказаний. Однако результаты практики назначения судами наказаний по конкретным уголовным делам будут существенны лишь в случаях распространенности этих деяний. Традиционно в структуре преступности наиболее распространенными являются преступления против собственности (кража, мошенничество и др.), преступления, связанные с незаконным оборотом наркотических средств и психотропных веществ, нарушения правил безопасности дорожного движения и эксплуатации транспортных средств, хулиганство. Относительно стабильным в структуре преступности также остается уровень умышленного убийства (включая и покушение на убийство): в 2000 г. - 325; 2005 г. - 288; 2010 г. - 276; 2011 г. - 270; 2012 г. - 276; 2013 г. - 281; 2014 г. $-298 ; 2015$ г. $-283 ; 2016$ г. $-245 ; 2017$ г. $-259 ; 2018$ г. $-262^{2}$.

При этом разнобой в судебной практике даже по отношению к вопросам наказуемости за умышленное убийство довольно существенен, что ещё раз подчеркивает необходимость ограничения судейского усмотрения при помощи конструирования санкций в более узких пределах между минимальным и максимальным наказанием. В связи с этим следовало бы систематизировать отягчающие обстоятельства умышленного убийства и дифференцировать уголовную ответственность не на двух, а на трех уровнях. Так, учитывая возрастание в последние годы внутрисемейного насилия, следует ввести в качестве отягчающего обстоятельства: убийство, совершенное в отношении близких родственников («внутрисемейное убийство»), а также убийство, совершенное в отношении несовершеннолетнего. В нашем законодательстве сложилась ситуация, когда похищение, захват в заложники или изнасилование, совершенные в отношении несовершеннолетнего, выступает в качестве критерия дифференциации уголовной ответственности, а уголовная ответственность за убийство несовершеннолетнего не дифференцируется. Исходя из указанных обстоятельств, можно прийти к ложному выводу, что половая неприкосновенность и личная свобода несовершеннолетних находятся в большей степени под уголовно-правовой охраной, нежели жизнь несовершеннолетнего. И подобных примеров в уголовном законе, связанных с неувязками дифференциации уголовной ответственности и построения санкций, множество.

В теории уголовного права существует мнение, что оптимальные размеры санкций должны устанавливаться на основе степени общественной опасности и распространенности деяния, объективных и субъективных признаков преступления, степени общественной опасности личности преступника, уровня общественного правосознания ${ }^{3}$. На наш взгляд, распространенность деяния, формирующая обширную судебную практику, позволяет в наибольшей степени оптимизировать санкцию конкретного деяния. В любом случае построению конкретной санкции на законодательном уровне должно предшествовать обобщение судебной практики по конкретным делам и доктринальное изучение судебной практики на основе аргументированных положений науки уголовного права. Поэтому чем выше распространенность деяния, тем обширнее станет судебная практика, тем многообразнее будут конкретные обстоятельства совершения деяния, разнообразнее свойства личностей, совершающих эти преступления. Однако учет разнообразия и практики уголовных дел при построении санкций должен приводить к увеличению уровня дифференциации уголовной ответственности, а не построению санкций с широкой амплитудой между минимальным и максимальным наказанием. В последнем случае не исключен судебный произвол, прикрывающийся принципом индивидуализации наказания.

Таким образом, влияние распространенности деяния на построение санкции носит не прямой, а косвенный характер. Распространенность преступления приводит к разнообразию обстоятельств совершения преступления, которые соответственно должны увеличивать или снижать степень общественной опасности деяния, что должно также учитываться при построении санкций за эти преступления. В этом случае законодатель будет стоять перед выбором:

1) расширить пределы санкций, чтобы были учтены, по возможности, все особенности конкретного случая, или же 
2) выделять квалифицирующие (реже - смягчающие) уголовную ответственность обстоятельства и повышать уровень дифференциации уголовной ответственности.

Первый вариант направлен на расширение индивидуализации наказания при отправлении правосудия, второй - на углубление законодательной дифференциации уголовной ответственности. Ещё раз отметим, что мы считаем более предпочтительным второй вариант.

Интересны также критические высказывания А.П. Козлова в связи с «отсутствием четких критериев классификации факторов, влияющих на определение пределов санкции». Полностью можно согласиться с мыслью автора, что учет личности и степени ее опасности не могут существовать вне обстоятельств, определяющих объективные и субъективные признаки состава преступления, т.е. все же первичны признаки состава преступления (характер и степень общественной опасности деяния, который определяется на основании всех признаков состава преступления), а потом уже особенности личности преступника ${ }^{4}$. А.П. Козлов также поддерживает выводы С.И. Дементьева, полагающего, что устанавливать санкцию с учетом распространенности деяния неверно, поскольку при таком подходе будет невозможно соблюсти принцип стабильности санкций 5 .

По мнению А.П. Козлова, «учет распространенности деяния тесно связан с общей превенцией как целью наказания, между тем наказание не назначается специально в целях общей превенции», «общая превенция существует лишь постольку, поскольку назначено конкретное наказание конкретному лицу, цель общей превенции не находит самостоятельного отражения в санкции» ${ }^{6}$. На наш взгляд, это не совсем верное рассуждение, т.к. наличие самой системы уголовно-правовых санкций с момента уже опубликования уголовного закона рассчитано на достижение цели общей превенции. И поэтому цель общей превенции выражена как в целостной системе санкций, так и в каждой санкции в отдельности. И хотя наказание конкретному виновному не назначается специально в целях общей превенции, но каждое своевременное осуждение виновного строго в соответствии с законом, в конечном счете, преследует общепредупредительную цель.

Действующий УК Азербайджанской Республики 1999 г. по сравнению с предыдущими УК 1960 г. содержит в Общей части бо̀льшее число специальных правил назначения (освобождения) наказания. Все они направлены на дифференциацию уголовной ответственности или индивидуализацию уголовной ответственности и наказания путем корректировки пределов санкций статей Особенной части УК.

Вместе с тем существующий по действующему УК уровень формализации наказания считаем все же недостаточным (даже при наличии ст. 58 (общие начала назначения наказания), ст. 60 (назначение наказания при смягчающих обстоятельствах), ст. ст. 63-67 (назначение наказания за неоконченное преступление, за преступление, совершенное в соучастии, при рецидиве преступлений, по совокупности преступлений, по совокупности приговоров) и некоторых др., т.к. построение санкций с широкой амплитудой наказания, непоследовательность дифференциации уголовной ответственности, неограниченное применение ст. 62 (назначение более мягкого наказания, чем предусмотрено за данное преступление) и ст. 70 (условное осуждение), которые довольно широко применяются в судебной практике за тяжкие и особо тяжкие преступления, способствуют широкому судебному усмотрению при отправлении правосудия по уголовным делам.

Амплитуда срока лишения свободы в отдельных единичных санкциях является очень большой. Так, например, по ст. 220.1 (массовые беспорядки) УК суд может назначить наказание на срок от четырех до 12 лет лишения свободы. Ещё более увеличивается разрыв при построении альтернативных санкций. Например, по ст. 312.2 (дача взятки) суд может назначить наказание в виде штрафа от 2 до 4 тыс. манат, либо приговорить к лишению свободы на срок от четырех до восьми лет, т.е. минимальное наказание по этой санкции - 2 тыс. манат несопоставимо с максимальным - восемь лет лишения свободы. Таким образом, санкция ст. 312.2 охватывает пределы типовых санкций трех категорий - преступлений, не представляющих большой общественной опасности, менее тяжких и тяжких преступлений.

Для современной науки и практики уголовного права вопрос о судейском усмотрении является очень актуальным. Положительный пример по отношению к пределам судейского усмотрения встречался в санкциях дореволюционного уголовного законодательства, когда пределы минимального и максимального наказания составляли в большинстве санкций два-три года, которыми и ограничивалось судейское усмотрение. Полная противоположность подобного подхода - революционное уголовное законодательство, а именно первые два УК Азербайджанской ССР (1922 г. и 1927 г.), в которых наказание в виде лишения свободы в санкциях указывалось с определением либо нижнего предела, либо верхнего, а расстрелу в санкции альтернативно могло быть указано наказание сроком в три месяца лишения свободы.

Следует заметить, что среди практических работников отношение к сужению пределов судейского усмотрения скорее отрицательное. Так, М.А. Агазаде, имеющий большой стаж работы в качестве судьи, в том числе и члена Верховного Суда Азербайджанской Республики, указывает на узкие пределы санкции за изготовление, приобретение или сбыт поддельных денег или ценных бумаг в ст. 204.1 (от пяти до семи лет лишения свободы) в УК 1999 г., в то время как в УК 1960 г. санкция аналогичной статьи предусматривала лишение свободы от трех до 15 лет $^{7}$. Мы согласиться с этим мнением никак не можем, т.к. в отличие от УК 1960 г. законодатель дифференцировал уголовную ответственность за указанное преступление на трех уровнях и особо квалифицированный состав преступления в ст. 204 влечет наказание в виде лишения свободы на срок от восьми до 12 лет. Из этого наглядного примера можно прийти к следующему выводу: повышение уровня дифференциации уголовной ответственности обратно пропорционально пределам судейского усмотрения. И, на наш взгляд, это более справедливо и законно. 
Анализ санкций Особенной части УК Азербайджанской Республики 1999 г. показывает, что во многих из них установлены слишком широкие пределы наказания, которые охватывают типовые санкции двух, а иногда и трех категорий преступлений. Имеются проблемы также при конструировании санкций статей, предусматривающих ответственность за смежные виды преступлений, которые не согласованы между собой. Подобную несогласованность санкций можно наблюдать при сравнении санкций общей и специальной нормы, а также санкций основного, квалифицированного и особо квалифицированного состава одного и того же вида преступления. Принцип согласованности санкций Особенной части нарушается также при введении изменений и дополнений в действующий УК 1999 года. Так, криминализация новых деяний в УК зачастую ведет к разбалансированию системы санкций Особенной части.

Таким образом, в действующем уголовном законодательстве Азербайджанской Республики построение санкций носит необоснованный характер. Анализ судебной практики уголовных дел по конкретным делам показывает расхождение в подходах к размеру наказания у законодателя и правоприменителя. В судебной практике назначение наказаний носит хаотический характер и зачастую не поддается логике. Наличие в Общей части норм и положений, позволяющих суду при назначении наказания выходить за пределы конкретной санкции совершенного деяния (ст. ст. 62, 70 и др.), позволяет нам утверждать, что функцию дифференциации ответственности фактически выполняет не законодатель, как это должно быть, а судебная власть.

Так, суд при определении конкретного размера наказания вправе по своему усмотрению, с учетом исключительных обстоятельств, связанных с целями и мотивами преступления, ролью виновного, его поведением во время или после совершения преступления и других обстоятельств, существенно уменьшающих степень общественной опасности преступления и т.д. (ст. 62), назначить наказание ниже нижнего предела или более мягкий вид наказания, чем предусмотрено соответствующей статьей УК, или не применить дополнительный вид наказания, предусмотренный в качестве обязательного. Применение в каждом конкретном случае ст. 62 УК должно быть строго мотивировано. Как видно из ее содержания, оценка тех или иных обстоятельств как исключительных - всецело прерогатива суда, отправляющего правосудие по конкретному уголовному делу. Чаще всего в судебной практике исключительными признаются совершение деяния впервые, положительная характеристика с места жительства или с места работы и наличие несовершеннолетних детей. Все указанные обстоятельства по своему характеру не являются исключительными, т.к. перечислены в ст. 59 Общей части УК и должны быть учтены при индивидуализации наказания в рамках конкретной санкции Особенной части УК. Применение же ст. 62 основывается на исключительных обстоятельствах. Итак, судебная практика исходит из позиции, что в качестве исключительных обстоятельств для применения ст. 62 могут выступать два и более смягчающих наказание обстоятельства, указанные в ст. 59 УК. На наш взгляд, применение смягчающих наказание обстоятельств в качестве исключительных возможно только в том случае, если эти смягчающие обстоятельства снижают степень общественной опасности совершенного деяния, а не выступают просто как характеристика личности или семейного положения виновного. Например, совершенно резонно спросить, как суд может мотивировать наличие у виновного несовершеннолетнего ребенка с причинением тяжкого вреда здоровью из хулиганских побуждений?8.

Ещё одна проблема, связанная с построением санкции в Особенной части УК, заключается в следующем. Дифференциация уголовной ответственности в Особенной части УК посредством выделения основных, квалифицированных и особо квалифицированных составов предполагает построение санкций с признаком усиления наказания. Однако построение санкций с широкой амплитудой между минимальным и максимальным пределами сроков лишения свободы ведет к тому, что пределы санкций за особо квалифицированные, квалифицированные и основные составы частично совпадают, что дает возможность суду назначить идентичное наказание за основной и квалифицированные виды преступлений. Подобное положение нарушает как принцип справедливости, так и принцип равенства перед законом и судом.

Нельзя не учитывать при этом и значение общепредупредительного воздействия наказания. Когда совпадают пределы наказания в санкциях с основным и квалифицированным составами, то общепредупредительный эффект дифференциации уголовной ответственности в пределах одной статьи теряет смысл. А «для общего предупреждения необходимо реальное применение принуждения»9.

Мнение некоторых авторов, что в вопросах отправления правосудия по уголовным делам ввиду отсутствия четких теоретических предписаний по конструированию санкций следует больше полагаться на судейское усмотрение и с этой целью следует повышать «правосознание судей, повышая уровень их правовой идеологии, усиливая роль научных взглядов, а это, в свою очередь, будет способствовать реальному восприятию ими объективной действительности» 10 , нам кажется неадекватным в существующих реалиях. По нашему мнению, легче добиться законодательно обоснованного построения санкций, нежели пытаться «целенаправленно воздействовать на правосознание судей, повышая уровень их правовой идеологии». Процесс изменения правосознания довольно длительный и, скажем честно, призрачный процесс. Между тем ничто так негативно не отражается на формировании общественного сознания у населения о справедливости и целесообразности уголовной политики государства, как судебный произвол. К сожалению, построение санкций с широкими пределами минимального и максимального размера наказания, большого числа альтернативных санкций с несколькими видами наказаний, а также возможность безограничительно применять ст. 62 (назначение более мягкого наказания, чем предусмотрено за данное преступление) и ст. 70 (условное осуждение) в Общей части действующего УК благоприятствуют судейскому произволу. 


\section{Гість номера}

На широкие пределы санкций, как негативное явление, в последние годы указывают многие ученые11. Зачастую в УК Азербайджанской Республики альтернативные санкции содержат виды наказаний, размеры которых по тяжести несоизмеримы (например, штраф в 500 манат и лишение свободы на 7 лет). Кроме того, встречаются альтернативные санкции, содержащие наряду с лишением свободы вид наказаний, не связанный с лишением свободы, за менее тяжкие и даже за тяжкие преступления. Как неоднократно утверждалось в наших ранних исследованиях, границы типовых санкций должны быть определены четко: максимальный предел санкции за преступления, не представляющие большой общественной опасности (до двух лет лишения свободы), являлся бы минимальным пределом менее тяжких преступлений (от двух до семи лет лишения свободы), и т.п. ${ }^{12}$

Из всех частей структуры уголовно-правовой нормы санкция считается наиболее легко и часто изменяемой частью нормы. Изменение карательной политики государства, направленное на усиление или, наоборот, смягчение уголовной ответственности в тот или иной отрезок времени, сразу же ведет к изменениям санкций. Такой опыт неоднократно имел место и в УК 1999 г., когда не только изменялись пределы наказания в санкциях, но в целом изменялась регламентация отдельных видов наказания (например, штрафа, общественных работ, лишения свободы) или даже исключался вид наказания (ограничение свободы, конфискация имущества), и это все находило свое отражение в конкретных санкциях Особенной части УК. Например, Закон Азербайджанской Республики от 30 мая 2014 г. внес изменения во все альтернативные санкции особо тяжких преступлений, подняв в них максимальный срок лишения свободы на определенный срок до 20 лет. Кроме того, были значительно ужесточены санкции ст. ст. 120.1, 214.1, 275.1, 282, 287 и др. В результате ужесточения санкции основные составы умышленного убийства (ст. 120.1) и терроризма (ст. 214.1) перешли из категории тяжких в категорию особо тяжких преступлений.

Кроме того, в науке уголовного права имеется такое понятие, как «социальная ценность и ее оценка в уголовном праве» 13 . С точки зрения социальной ценности, трудно объяснить подход законодателя Азербайджанской Республики (в РФ наказание за сходные деяния соразмеримо) при сравнении санкций за посягательство на жизнь государственного или общественного деятеля (ст. 277) и за посягательство на жизнь лица, осуществляющего правосудие или предварительное расследование (ст. 287), или же санкций за угрозу и насильственные действия в связи с осуществлением правосудия (ст. 288.1) и производством предварительного расследования (ст. 288.2). В обоих случаях мы констатируем нарушение конституционного принципа «равенства всех перед законом и судом»: в первом случае (ст. 287) жизнь лиц, осуществляющих правосудие или предварительное расследование, находится под менее строгой уголовно-правовой защитой, чем жизнь государственного или общественного деятеля (ст. 277), во втором - прокуроры, следователи и другие лица, указанные в ст. 288.2 УК, защищаются менее строго, нежели судьи или иные лица, указанные в ст. 288.1 УК. Мы неоднократно отмечали, что построение единичной санкции в ст. 287 также нарушает конституционный принцип равенства всех трех ветвей власти - исполнительной, законодательной и судебной. К сожалению, Закон Азербайджанской Республики от 30 мая 2014 г., в целом ужесточив санкцию ст. 287, все же не привел в соответствие санкции ст. 120.2.3 (умышленное убийство потерпевшего или его близких в связи с осуществлением данным лицом служебной деятельности или выполнением общественного долга), ст. 277 (посягательство на жизнь государственного или общественного деятеля) и ст. 287 (посягательство на жизнь лица, осуществляющего правосудие или предварительное расследование) УК.

И в заключение статьи еще раз отметим, что санкции Особенной части УК Азербайджанской Республики 1999 г., с учетом достижений науки и практики уголовного права, должны быть пересмотрены и сконструированы заново в системном порядке.

1 Загородников Н.И. Классификация преступлений и ее значение для деятельности органов внутренних дел. Москва: МВШМ МВД СССР, 1983. 83 с. С. 46.

2 Преступность и правонарушения в Азербайджане.: стат. сб. 2018. URL: https://www.stat.gov.az/source/crimes/

3 Игнатов А.Н., Костарева Т.Д. Уголовная ответственность и состав преступления. Уголовное право. Общая часть: Курс лекций. Москва: ИНФРА-М-НОРМА, 2003. С. 60.

${ }^{4}$ Козлов А.П. Уголовно-правовые санкции: Проблемы построения, классификации и измерения. Красноярск: Изд. Краснояр. ун-та, 1986. С. 134.

5 Дементьев С.И. Построение уголовно-правовых санкций в виде лишения свободы. Ростов: Ростовский ун-т, 1986, 157 c. C. 151.

${ }^{6}$ Козлов А.П. Уголовно-правовые санкции: Проблемы построения, классификации и измерения. Красноярск: Изд. Краснояр. ун-та, 1986, 152 с. С. $132-133$.

7 Агазаде М.А. Размышления судьи об уголовном и уголовно-процессуальном законодательствах. Баку: Юридическая литература, 2009. С. 34.

8 Бюллетень Верховного Суда Азербайджанской Республики. Баку. 2013. № 2. С. 11.

9 Марцев А.И., Максимов С.В. Общее предупреждение преступлений и его эффективность. Томск: Изд. Томск. Гос. унта, 1989. 233 с. С. 22.

10 Осипов П.П. Теоретические основы построения и применения уголовно-правовых санкций (аксиологические аспекты). Ленинград: Изд. Ленингр. ун-та. 1976. 134 с. С. 75-76.

11 Зубкова В. Проблемы построения и взаимообусловленности санкций и категорий преступлений в УК РФ. Уголовное право: ежеквартальный научно-практический журнал. Москва, 2002. № 4. С. 18-20; Михаль О. Судейское усмотрение при 
назначении наказания. Уголовное право. 2004. № 4. С. 36-38; Рарог А.И., Грачева Ю.В. Законодательная техника как средство ограничения судейского усмотрения. Государство и право. 2002. № 11. С. 93-95, 98-100, 158.

12 Самедова Ш.Т. Категории преступлений. Баку: Адильоглы, 2007, 314. С. 280-281.

13 Трахов А. Конструирование диспозиций статей с различными по степени тяжести составами преступлений. Уголовное право. 2002. № 2. С. 62.

References:

Zagorodnikov, N.I. (1983). Klassifikatsiya prestupleniy i ee znachenie dlya deyatelnosti organov vnutrennih del. M.: MVShM MVD SSSR [in Russian]. Russian].

Prestupnost i pravonarusheniya v Azerbaydzhane. Statisticheskiy sbornik, 2018. URL: https://www.stat.gov.az/source/crimes/ [in

Ignatov, A.N., Kostareva T.D. (2003). Ugolovnaya otvetstvennost i sostav prestupleniya // Ugolovnoe pravo. Obschaya chast: Kurs lektsiy. M.: INFRA-M-NORMA [in Russian].

Kozlov, A.P. (1986). Ugolovno-pravovyie sanktsii: Problemyi postroeniya, klassifikatsii i izmereniya. Krasnoyarsk: izd. Krasnoyar. Un-ta [in Russian].

Dementev, S.I. (1986). Postroenie ugolovno-pravovyih sanktsiy v vide lisheniya svobodyi. Rostov: Rostovskiy Un-t [in Russ-

Kozlov, A.P. (1986). Ugolovno-pravovyie sanktsii: Problemyi postroeniya, klassifikatsii i izmereniya. Krasnoyarsk: izd. Krasnoyar. Un-ta [in Russian].

Agazade, M.A. (2009). Razmyishleniya sudi ob ugolovnom i ugolovno-protsessualnom zakonodatelstvah. Baku: Yuridicheskaya literature [in Russian].

Byulleten Verhovnogo Suda Azerbaydzhanskoy Respubliki. (2013). Baku, 2, 11 [in Russian]. [in Russian].

Martsev, A.I., Maksimov, S.V. (1989). Obschee preduprezhdenie prestupleniy i ego effektivnost. Tomsk: izd. Tomsk. Gos. un-ta

Osipov, P.P. (1976). Teoreticheskie osnovyi postroeniya i primeneniya ugolovno-pravovyih sanktsiy (aksiologicheskie aspektyi). Leningrad: izd. Leningr. Un-ta [in Russian].

Zubkova, V. (2002). Problemyi postroeniya i vzaimoobuslovlennosti sanktsiy i kategoriy prestupleniy v UK RF. Ugolovnoe pravo: Ezhekvartalnyiy nauchno-prakticheskiy zhurnal. 4, 18-20 [in Russian].

Mihal, O. (2004). Sudeyskoe usmotrenie pri naznachenii nakazaniya. Ugolovnoe pravo. 4, 36-38 [in Russian].

Rarog A.I., Gracheva, Yu.V. (2002). Zakonodatelnaya tehnika kak sredstvo ogranicheniya sudeyskogo usmotreniya. Gosudarstvo i pravo. 11, 93-95, 158, 98-100 [in Russian].

Samedova, Sh.T. (2007). Kategorii prestupleniy. Baku: Adiloglyi [in Russian]

Trahov, A. (2002). Konstruirovanie dispozitsiy statey s razlichnyimi po stepeni tyazhesti sostavami prestupleniy. Ugolovnoe pravo. 2, 62 [in Russian].

\section{Резюме}

Шахла Самедова. Про побудову санкцій і формалізації призначення покарання в кримінальному праві в Азербайджанській Республіці.

На думку автора, недосконалість деяких інститутів Загальної частини, а також численні зміни та доповнення, внесені в Особливу частину, привели в цілому неузгодженості системи санкцій в чинному КК Азербайджанської Республіки. Тому побудова більшості санкцій Особливої частини КК Азербайджанської Республіки має бути змінено з метою посилення формалізації призначення покарання. Однак це питання потребує системного вирішення і для успішного вирішення цього завдання Загальна частина КК повинна бути істотно реформована. Передусім слід усунути недоліки, пов'язані із законодавчою класифікацією злочинів.

Ключові слова: кримінальне право, кримінальне покарання, формалізація призначення покарання, санкція, побудова санкцій, альтернативна санкція, кумулятивна санкція, одинична санкція, щодо-певна санкція.

\section{Резюме}

Шахла Самедова. О построении санкций и формализации назначения наказания в уголовном праве в Азербайджанской Республике.

По мнению автора, несовершенство некоторых институтов Общей части, а также многочисленные изменения и дополнения, внесенные в Особенную часть, привели в целом к рассогласованности системы санкций в действующем УК Азербайджанской Республики. Поэтому построение большинства санкций Особенной части УК Азербайджанской Республики должно быть изменено с целью усиления формализации назначения наказания. Однако этот вопрос требует системного решения и для успешного решения этой задачи Общая часть УК должна быть существенно реформирована. Прежде всего, следует устранить недостатки, связанные с законодательной классификацией преступлений.

Ключевые слова: уголовное право, уголовное наказание, формализация назначения наказания, санкция, построение санкций, альтернативная санкция, кумулятивная санкция, единичная санкция, относительно-определенная санкция.

\section{Summary}

Shahla Samadova. On construction of sanctions and formalization of purpose of punishment in Criminal law of the Republic of Azerbaijan.

According to the author, the construction of most of the sanctions Special Part of the Criminal Code Republic of Azerbaijan should be changed in order to strengthen the formalization of sentencing. However, this issue requires a systematic solution and for the successful solution of this task, the criminal law should be substantially reformed. The current Criminal Code of the Republic of Azerbaijan, adopted on December 30,1999, contains many fundamentally new positions and norms, some of which, unfortunately, are not 


\section{Гість номера}

without drawbacks. In addition, during the period of the Criminal Code, many changes and additions were made to it (more than one third of all the norms of the Special Part), which were not always agreed upon with other norms and institutions. In the current edition of the Criminal Code, the differentiation of criminal responsibility is inconsistent in both the General and Special Parts, which is mainly due to the imperfection of the main criterion for differentiation of criminal liability - the institution of classification of crimes. The imperfection of the institution of classification of crimes and the inconsistency in the differentiation of criminal liability could not but affect the very principle of constructing criminal sanctions in the Special Part, which play a decisive role in determining the categories of specific crimes. The main drawback of the sanctions system of the Special Part is their inconsistency, both among themselves and with typical sanctions of crime categories. The sanctions of the main, qualified and highly qualified convictions in the vast majority of cases coincide, which in practice leads to the imposition of punishments that do not correspond to the committed categories of crimes. The types of sanctions (single, alternative, cumulative) for various categories of crime are not always optimally determined. Relatively defined sanctions in the Criminal Code often have too wide limits between the minimum and maximum sentences (especially in alternative designs), which leads to wide judicial discretion. In addition, the wide limits between the minimum and maximum sentences in most cases cover the boundaries of typical sanctions of two or more categories of crimes, which lead to an imbalance between the specific punishment imposed by the court and the consequences of the crime. All this substantially violates the principles of the equality of all before the law and the court (Article 6 of the Criminal Code) and the justice of criminal law and criminal liability (Article 8 of the Criminal Code). At the same time, improving the institution of classification of crimes is a rather complicated and intractable process both theoretically and in practice, as their resolution is actually aimed at a complete reform of the sanctions of the Special Part, as well as a rethinking of a number of conceptual provisions of the General Part of the criminal law. Coordination of the sanctions system of the Special Part of the Criminal Code is possible subject to the principles of building sanctions in accordance with the Constitution of the Republic of Azerbaijan and the basic principles and norms of international law, as well as general legal principles of the criminal law. Given the systemic nature of the criminal law, when making additions and changes to the General Part, as well as to the Special Part of the Criminal Code, the new rules should be agreed overall with the sanctions system of the Special Part of the Criminal Code. When constructing sanctions in the Special Part of the Criminal Code, the prevalence of the principle of individualization of punishment and, consequently, the expansion of judicial discretion over the legislatively defined differentiation of criminal liability violates not only the principle of justice of the criminal law, but also the constitutional provision on the equality of citizens before the law and the court. Appealing to the principle of humanity in the provision of broad powers to the court to individualize punishment is considered unreasonable, because the specific nature of the tasks of criminal law still determines, in our opinion, the supremacy of the principle of justice. Moreover, the principle of humanity has been sufficiently taken into account when regulating many provisions and norms of the General Part of the Criminal Code of the Azerbaijan Republic (Articles 62, 70 and others).

Key words: criminal law, criminal punishment, formalization of sentencing, sanction, construction of sanctions, alternative sanction, cumulative sanction, single sanction, relatively specific sanction. 